\title{
Ceratocone unilateral associado a constante massagem ocular devido à obstrução da via lacrimal - Relato de caso
}

\author{
Unilateral keratoconus associated with continual eye rubbing due to nasolacrimal \\ obstruction - Case report
}

\author{
Cristiano Menezes Diniz ${ }^{1}$ \\ Patrick Frensel de Moraes Tzelikis ${ }^{2}$ \\ Alair Rodrigues Júnior ${ }^{3}$ \\ Heriberto da Silva Alvim ${ }^{3}$ \\ Raquel R. A. Dantas ${ }^{4}$ \\ Ana Rosa Pimentel de Figueredo ${ }^{5}$
}

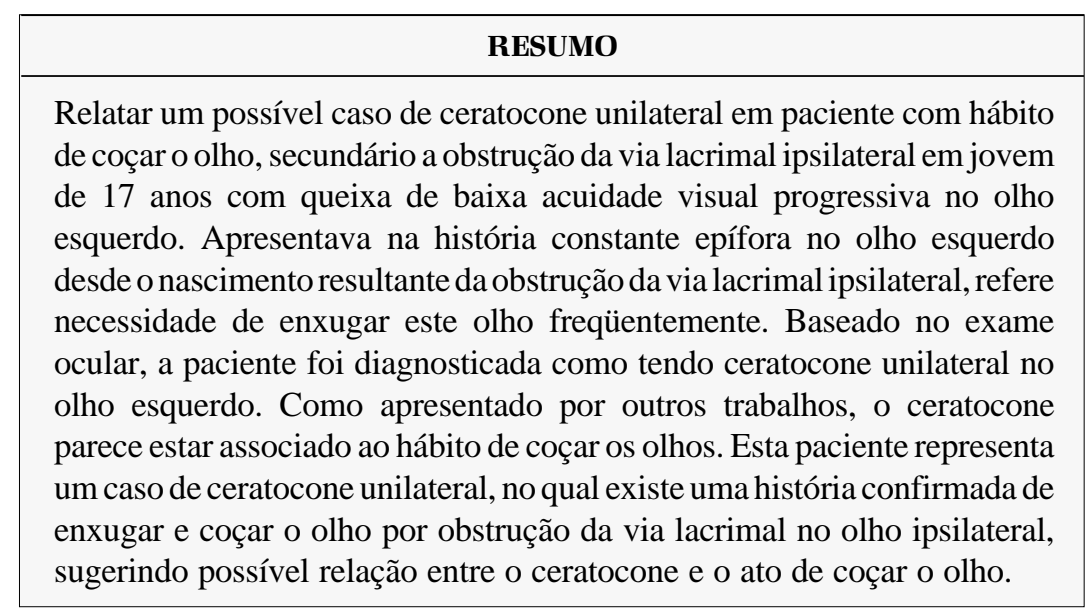

Descritores: Ceratocone/etiologia; Olho/patologia; Doenças do aparelho lacrimal; Relatos de casos [Tipo de Publicação]

\section{INTRODUÇ̃̃̃O}

Ceratocone é uma distrofia ectásica corneana progressiva, caracterizada por um afilamento e protusão da córnea central ou paracentral, que acaba por assumir uma forma cônica ${ }^{(1)}$. Geralmente, é uma doença bilateral, mas freqüentemente assimétrica. $\mathrm{O}$ ceratocone verdadeiramente unilateral é raro; embora apenas um olho possa ser acometido no início ${ }^{(2-3)}$. Dados da literatura apresentam uma redução na incidência de ceratocone unilateral, fato ocorrido após a introdução de topografia corneana computadorizada com identificação de ceratocone em olhos anteriormente dados como normais $^{(4-5)}$.

Apesar do ceratocone estar associado a várias doenças oculares e sistêmicas como ceratoconjuntivite vernal ${ }^{(6)}$, dermatite atópica ${ }^{(7)}$, síndrome da flacidez palpebral ${ }^{(8)}$, amaurose de Leber ${ }^{(9)}$, retinose pigmentar ${ }^{(10)}$, síndrome de Down ${ }^{(11)}$, síndrome de Ehler-Danlos ${ }^{(12)}$, e outras, até hoje existem dúvidas quanto a sua etiologia, hereditariedade, patogênese e bioquímica. O caráter hereditário do ceratocone não é claro, mas história familiar positiva já foi relatada em $6 \%-8 \%$ dos $\operatorname{casos}^{(13)}$. Estudos recentes sugerem um padrão de herança com penetrância incompleta, porém a maioria dos casos ainda é esporádica ${ }^{(13)}$.

A apoptose celular, ou seja, uma espécie de morte celular programada onde, sob mediação de vários fatores, as células danificadas ou sem função são eliminadas, parece ter forte associação com o ceratocone. Em córneas com ceratocone, o índice de apoptose dos ceratócitos estromais é bem maior que em córneas normais ${ }^{(14-15)}$. 
Um dos maiores fatores etiológicos sugeridos na gênese do ceratocone é o freqüente ato de coçar os olhos ${ }^{(16)}$. O ceratocone parece estar diretamente ligado ao ato de massagear os olhos $^{(17-18)}$. Este trabalho apresenta um caso de ceratocone unilateral, na qual se observa na história do paciente um hábito constante de enxugar e coçar o olho, secundário a constante epífora resultante de uma obstrução da via lacrimal ipsilateral, sugerindo uma possível relação entre a massagem ocular e o desenvolvimento de ceratocone. O olho contralateral não apresenta nenhuma alteração na via lacrimal e nenhum sinal de ceratocone comprovados através dos exames de lavagem das vias lacrimais, dacriocistografia e topografia de córnea.

\section{RELATO DE CASO}

Paciente do sexo feminino, 17 anos, atendida pela primeira vez no Hospital São Geraldo em agosto de 2002 com queixa de baixa de acuidade visual no olho esquerdo (OE) há aproximadamente 1 ano. Relata que, desde de o nascimento, apresenta epífora sem secreção em $\mathrm{OE}$ o que fez com que fosse criado o hábito de enxugar o olho várias vezes ao dia. Desde os 7 anos de idade usa correção visual apenas em OE, mas só recentemente foi diagnosticado ceratocone grau III/IV. A paciente nega história de qualquer tipo de atopia assim como problemas visuais em OD. Na família não existem casos de ceratocone ou outro problema oftalmológico importante.

Ao primeiro exame, a acuidade visual sem correção era de 20/20 em OD e pior que 20/400 em OE o qual melhorava para 20/ $60 \mathrm{com}-11,00-6,00 \times 45^{\circ}$. À biomicroscopia, não foram identificados sinais de conjuntivite alérgica estando OD completamente sem alterações e, em $\mathrm{OE}$, sinal de Mousson positivo com córnea bastante abaulada e estrias de Vogt no ápice. A pressão intra-ocular era de $14 \mathrm{mmHg}$ em $\mathrm{AO}$ e o fundo de olho era normal em AO. Um reflexo em tesoura foi observado na retinoscopia do OE enquanto no olho direito o reflexo era normal.

$\mathrm{Na}$ propedêutica de vias lacrimais, a paciente apresentou retenção de contraste importante apenas em OE (Milder +) com obstrução de vias lacrimais aparentemente ao nível de canal comum uma vez que a irrigação mostrou refluxo de soro por ambos os canalículos sem presença de secreção. A dacriocistografia evidenciou vias lacrimais sem alterações à direita e, à esquerda, não foi observado aparecimento de contraste na via lacrimal assim como o saco lacrimal apresentava-se aparentemente normal (Figura 1).

A topografia computadorizada mostra um gráfico topográfico indicativo de ceratocone avançado no olho $\mathrm{OE}$ com curvaturas de 75,30x66,38. A topografia corneana do OD revela um astigmatismo a favor da regra sem evidencia de ceratocone, com curvaturas de 46,15x45,06 (Figuras $2 \mathrm{e} 3$ ). A paquimetria corneana foi de $501 \mathrm{~nm}$ em OD e 426nm em OE (Figuras 4 e 5).

A paciente foi submetida a uma cirurgia lacrimal endoscópica trans-punctal (via ponto lacrimal) à esquerda e será encaminhada ao serviço de Lentes de Contato para adaptação em OE.

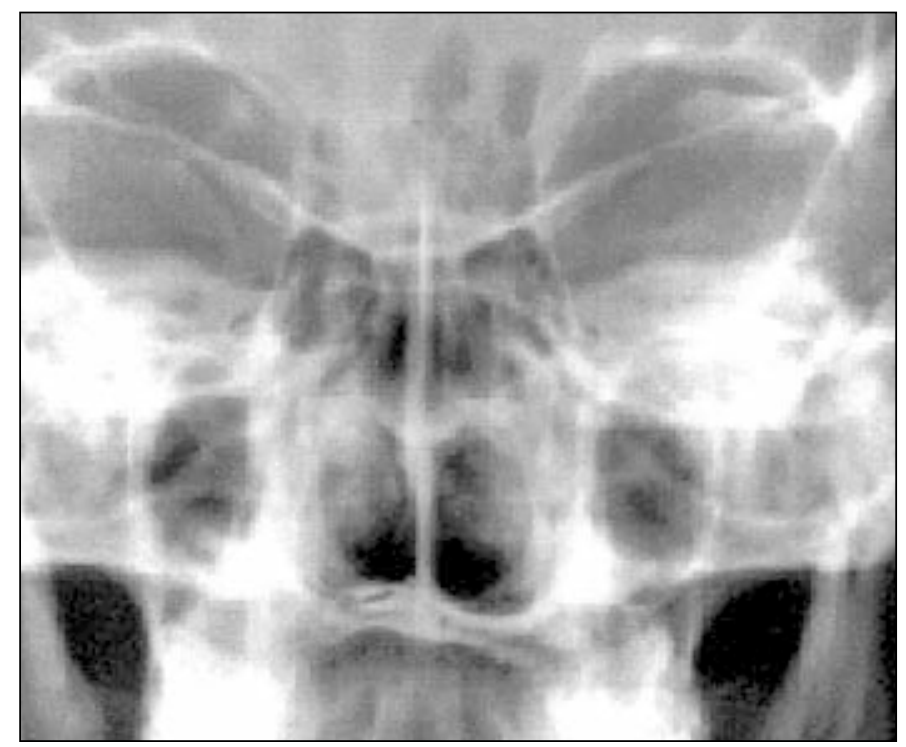

Figura 1 - Dacriocistografia. Observa-se presença de contraste na cavidade nasal apenas à direita

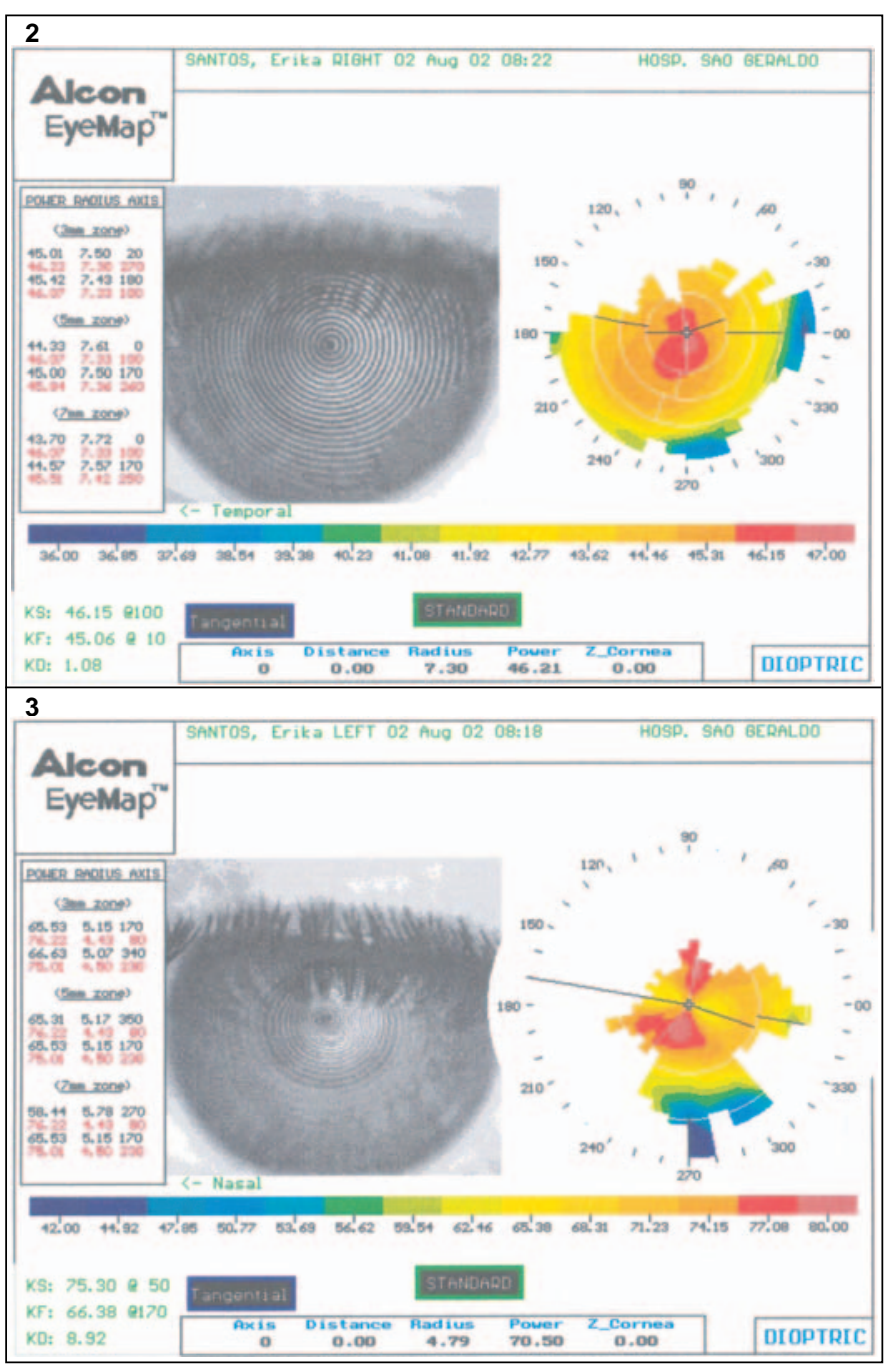

Figuras 2 e 3 - Topografia computadorizada de córnea 

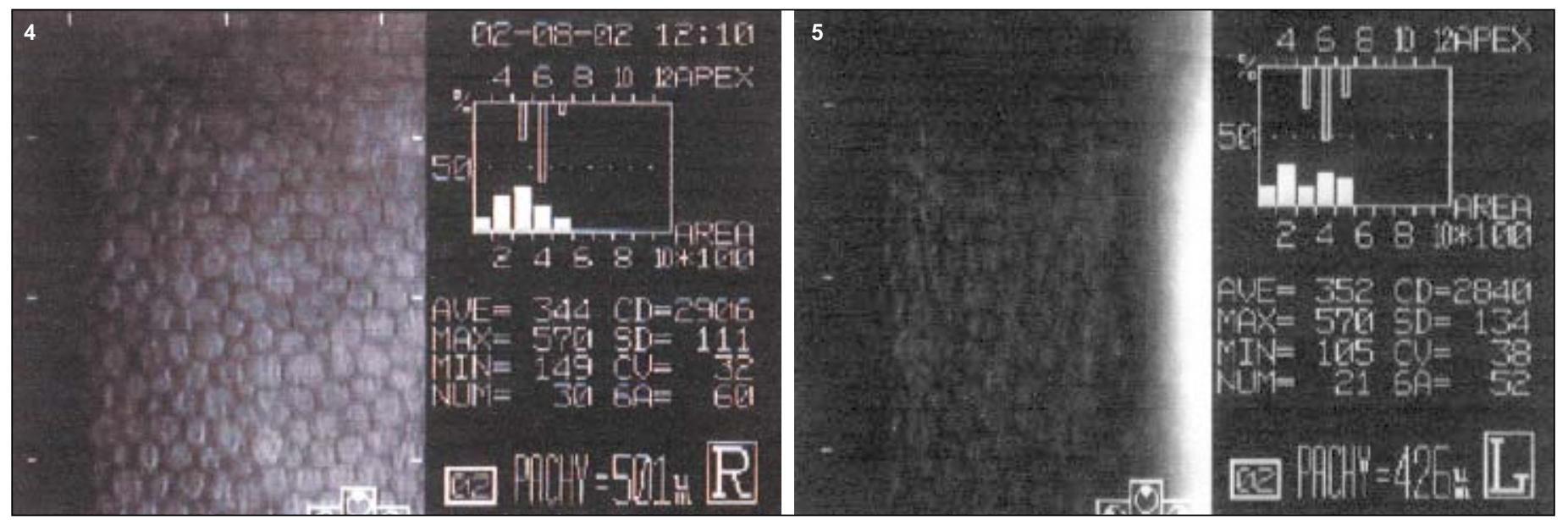

Figuras 4 e 5 - Paquimetria e microscopia especular de córnea

\section{DISCUSSÃO}

O presente trabalho tenta mostrar uma possível relação entre o hábito do paciente em enxugar e coçar o olho devido a epífora secundária à obstrução da via lacrimal ipsilateral e o desenvolvimento raro de ceratocone unilateral.

$\mathrm{O}$ ato de coçar os olhos vem sendo associado ao desenvolvimento de ceratocone em muitos trabalhos relatados na literatura ${ }^{(19)}$. Em 2000, foi relatado um caso de ceratocone unilateral em paciente com agenesia de ponto lacrimal e epífora com constante massagem ocular do lado acometido ${ }^{(20)}$. Em 2002, foi descrito um caso de ectasia corneana em um paciente com quadro de dacriocistocele, com 10 anos de evolução, que realizava massagem ocular freqüente ${ }^{(18)}$. Apesar de vários relatos na literatura, ainda não foi possível estabelecer uma causa-efeito.

No Brasil, estudou-se o caso de um jovem de 22 anos com ceratocone, aparentemente sadio, sem história de atopia, que, a princípio, negou qualquer manipulação ocular. Porem, após investigação mais detalhada, foi descoberto que o paciente era sonâmbulo e que, durante o sonambulismo, coçava os olhos vigorosamente ${ }^{(21)}$.

A patogênese do ceratocone permanece incerta. Trabalhos recentes apontam para apoptose de ceratócitos como fator de desenvolvimento do ceratocone ${ }^{(14-15,22)}$. Vários autores mostraram, através de técnicas especiais para coloração de células em apoptose (TUNEL e ssDNA), que o número de ceratócitos em apoptose é significativamente maior nas córneas com ceratocone que nas normais ${ }^{(14-15)}$. Fatores causadores de injúria epitelial crônica ou que determinam rápido "turn-over" epitelial, como usuários de lentes de contato, doenças que cursam com intensa manipulação ocular (massagem ocular) e atopias, causariam perda lenta de ceratócitos por apoptose resultando em afilamento estromal em pessoas suscetíveis ${ }^{(23)}$.

Ceratocone vem sendo encontrado em várias síndromes clínicas, sendo que muitas estão fortemente associadas ao constante ato de coçar os olhos ${ }^{(16)}$. Estudos mostram uma incidência de atopia maior em pacientes com ceratocone quando comparado a população em geral ${ }^{(19,24)}$. A alergia ocular caracteriza-se por uma reação de hipersensibilidade de intensidade variável, crônica e recorrente que apresenta como um dos seus principais sintomas o prurido. Existe uma alta incidência de ceratocone nestes pacientes ${ }^{(24)}$.

Existem publicações as quais associam massagem ocular ao ceratocone em dois terços dos seus pacientes ${ }^{(16)}$. Um caso, acompanhado prospectivamente, foi descrito também se associando massagem ocular ao ceratocone. Tratava-se de um garoto com arritmia cardíaca que descobriu que a sua arritmia poderia ser interrompida com massagem ocular vigorosa provavelmente por um reflexo oculocardíaco e com o tempo acabou por desenvolver ceratocone sem apresentar nenhum outro fator de risco ${ }^{(19)}$.

Trabalhos atuais tentam provar que pacientes com ceratocone coçam mais seus olhos que pacientes sem ceratocone, porém ainda não foi conclusivamente provado. No estudo colaborativo de avaliação longitudinal de ceratocone (CLEK), $48,2 \%$ dos pacientes coçam seus dois olhos vigorosamente, enquanto apenas $2,2 \%$ coçam apenas um olho ${ }^{(25)}$. O número de pacientes com ceratocone que coçam seus olhos varia de $12-80 \%$ na literatura ${ }^{(2,17-20)}$.

Este relato de caso não pode provar que o ato de coçar o olho possa causar ceratocone. No entanto, pode mostrar uma possível relação causal entre o ato de coçar os olhos e o ceratocone em alguns pacientes provavelmente susceptíveis.

\section{ABSTRACT}

To describe a possible case of unilateral keratoconus in a patient with continual eye rubbing due to an ipsilateral nasolacrimal obstruction in a 17-year-old woman complaint of progressing low visual acuity in the left eye. Presented with constant epiphora in the left eye throughout her life as a result of ipsilateral nasolacrimal obstruction, which required frequent wiping of this eye. Based on ocular examination, the 
patient was diagnosed as having unilateral keratoconus in the left eye. As in other studies, keratoconus is thought to be associated with persistent eye rubbing. This patient represents a case of unilateral keratoconus, where there is a confirmed history of habitual eye rubbing due to ipsilateral nasolacrimal obstruction, thereby suggesting a possible causal relationship between eye rubbing and keratoconus.

Keywords: Keratoconus/etiology; Eye/pathology; Lacrimal apparatus diseases; Case reports [Publication type]

\section{REFERÊNCIAS}

1. Wilhelmus KR, Huang AJW, Hwang DH, Parrish CM, Stuphin JE. External disease and cornea. Basic and clinical science course. Section 8. San Francisco: American Academy of Ophthalmology. 2000-2001. Pt 7, cap. 16, p.305-8.

2. Rabinowitz YS. Keratoconus. Surv Ophthalmol. 1998;42(4):297-319. Review.

3. Lawless M, Coster DJ, Phillips AJ, Loane M. Keratoconus: diagnosis and management. Aust N Z J Ophthalmol. 1989;17(1):33-60. Review.

4. Wilson SE, Lin DT, Klyce SD. Cornea topography of keratoconus. Cornea. 1991;10(1):2-8.

5. Rabinowitz YS, Nesburn AB, McDonell PJ. Videokeratography of the fellow eye in unilateral keratoconus. Ophthalmology. 1993;100(2):181-6.

6. Cameron JA, Al-Rajhi AA, Badr IA. Corneal ectasia in vernal keratoconjunctivitis. Ophthalmology. 1989;96(11):1615-23.

7. Sabiston DW. The association of keratoconus, dermatitis and asthma. Trans Ophthalmol Soc N Z. 1966;18:66-71.

8. Donnenfeld ED, Perry HD, Gibralter RP, Ingraham HJ, Udell IJ. Keratoconus associated with floppy eyelid syndrome. Ophthalmology. 1991;98(11):1674-8.

9. Karel I. Keratoconus in congenital diffuse tapetoretinal degeneration. Ophthalmologica. 1968;155(1):8-15.
10. Freedman J, Gombos GM. Bilateral macular coloboma, keratoconus, and retinitis pigmentosa. Ann Ophthalmol. 1971;3(6):664-5.

11. Cullen JF, Butler HG. Mongolism (Down's syndrome) and keratoconus. Br J Ophthalmol. 1963;47:321-30.

12. Robertson I. Keratoconus and Ehlers-Danlos syndrome: a new aspect of keratoconus. Med J Aust. 1975;1(18):571-3.

13. Rabinowitz YS, Garbus J, McDonnell PJ. Computer-assisted corneal topography in family members of patients with keratoconus. Arch Ophthalmol. 1990; 108(3):365-71.

14. Kaldawy, RM, Wagner, J, Ching, S, Seigel, GM. Evidence of apoptotic cell death in Keratoconus. Cornea 2002;21(2):206-9.

15. Kim WJ, Rabinowitz YS, Meisler DM, Wilson SE. Keratocyte apoptosis associated with keratoconus. Exp Eye Res. 1999;69(5):475-81.

16. Karseras AG, Ruben M. Aetiology of keratoconus. Br J Ophthalmol. 1976;60 (7):522-5.

17. Gritz DC, McDonnell PJ. Keratoconus and ocular massage. Am J Ophthalmol. 1988;106(6):757-8.

18. Lucarelli MJ, DeBry P. Corneal ectasia associated with massage of dacryocystoceles. Cornea. 2002;21(4):419-20.

19. Coyle JT. Keratoconus and eye rubbing. Am J Ophthalmol. 1984;97(4):527-8.

20. Lindsay RG, Bruce AS, Gutteridge IF. Keratoconus associated with continual eye rubbing due to punctal agenesis. Cornea. 2000;19(4):567-9.

21. Waisberg Y. Keratoconus in a patient with somnambulism and eye-pressing. CLAO J. 1991;17(2):79.

22. Holland DR, Maeda N, Hannush SB, Riveroll LH, Green MT, Klyce SD, Wilson SE. Unilateral keratoconus. Incidence and quantitative topographic analysis. Ophthalmology. 1997;104(9):1409-13.

23. Wilson SE, He YG, Weng J, Li Q, McDowall AW, Vital M, Chwang EL. Epithelial injury induces keratocyte apoptosis: hypothesized role for the interleukin-1 system in the modulation of corneal tissue organization and wound healing. Exp Eye Res. 1996;62(4):325-7

24. Bawazeer AM, Hodge WG, Lorimer B. Atopy and keratoconus: a multivariate analysis. Br J Ophthalmol. 2000;84(8):834-6.

25. Zadnik K, Barr JT, Edrington TB, Everett DF, Jameson M, McMahon TT, et al. Baseline findings in the Collaborative Longitudinal Evaluation of Keratoconus (CLEK) Study. Invest Ophthalmol Vis Sci. 1998;39(13):2537-46.

\section{CONGRESSO DA SOCIEDADE BRASILEIRA DE VISÃO SUBNORMAL}

\section{4 a 26 de Junho de 2005 Unique Hotel - São Paulo - SP}

IN FO RMAÇÕES: Tel.: (11) 3266-4000 c/ Fabrício

E-mail: congresso@ visaosubnormal.org.br

Home-page: www.visaosubnormal.org.br 